\title{
NEW KNOWLEDGE IN DETERMINING THE ASTRONOMICAL ORIENTATION OF INCAS OBJECT IN OLLANTAYTAMBO, PERU
}

\author{
K. Hanzalováa *, J. Klokočník ${ }^{b}$, J. Kosteleckýc \\ ${ }^{\text {a }}$ CTU in Prague, Faculty of Civil Engineering, Department of Geoinformation, Prague, Czech Republic; \\ karolina.hanzalova@fsv.cvut.cz \\ ${ }^{b}$ Astronomical Institute of the Academy of Sciences of the Czech Republic, Ondřejov Observatory, Czech \\ Republic,jklokocn@asu.cas.cz
}

${ }^{\mathrm{c}}$ CEDR, Research Institute for Geodesy, Topography and Cartography, Zdiby 98, Czech Republic, kost@fsv.cvut.cz

KEY WORDS: Ollantaytambo, astronomical orientation, astronomical azimuth, Pyramids Pacaritanpu, archeoastronomy, Peru

\begin{abstract}
:
This paper deals about astronomical orientation of Incas objects in Ollantaytambo, which is located about $35 \mathrm{~km}$ southeast from Machu Picchu, about $40 \mathrm{~km}$ northwest from Cusco, and lies in the Urubamba valley. Everybody writing about Ollantaytambo, shoud read Protzen (1993). He devoted his monograph to description and interpretation of that locality. Book of Salazar and Salazar (2005) deals, among others, with the orientation of objects in Ollantaytambo with respect to the cardinal direction. Zawaski and Malville (2007) documented astronomical context of major monuments of nine sites in Peru, including Ollantaytambo. We tested astronomical orientation in these places and confirm or disprove hypothesis about purpose of Incas objects. For assessment orientation of objects we used our measurements and also satellite images on Google Earth and digital elevation model from ASTER. The satellite images used to approximate estimation of astronomical orientation. The digital elevation model is useful in the mountains, where we need the really horizon for a calculation of sunset and sunrise on specific days (solstices), which were for Incas people very important. By Incas is very famous that they worshiped the Sun. According to him they determined when to plant and when to harvest the crop. In this paper we focused on Temple of the Sun, also known the Wall of six monoliths. We tested which astronomical phenomenon is connected with this Temple. First, we tested winter solstice sunrise and the rides of the Pleiades for the epochs 2000, 1500 and 1000 A.D. According with our results the Temple isn't connected neither with winter solstice sunrise nor with the Pleiades. Then we tested also winter solstice sunset. We tried to use the line from an observation point near ruins of the Temple of Sun, to west-north, in direction to sunset. The astronomical azimuth from this point was about $5^{\circ}$ less then we need. From this results we found, that is possible to find another observation point. By Salazar and Salazar (2005) we found observation point at the corner (east rectangle) of the pyramid by Pacaritanpu, down by the riverside. There is a line connecting the east rectangular "platform" at the river, going along the Inca road up to vicinity of the Temple of the Sun and then in the direction to the Inca face. Using a digital elevation model we found the astronomical azimuth, which is needed for confirm astronomical orientation of the Temple. So, finally we are able to demonstrate a possibility of the solar-solstice orientation in Ollantaytambo.
\end{abstract}

\section{INTRODUTION}

Determination of astronomical azimuth of sunrise or sunset at solstice of important objects in north-eastern Peru was written by many authors (e.g. Malville 2010, Gullberg 2010, Salazar and Salazar 2005). Figures 1 shows the astronomical azimuths of the Sun for the geographic latitude of Cusco area, for sunrise and sunset at solstices. June 21 or 22 is the day of the winter solstice in the southern hemisphere. The Sun rises at the astronomical azimuth 66 degrees or 24 degrees North of East, provided that we can observe the Sun at ideal horizon (elevation 0 degrees or zenith distance 90 degrees). December 21 st or $22 \mathrm{nd}$ is the day of their summer solstice. The Sun rises at 114 degrees East of North, or 24 degrees South of East. The azimuths of sunsets are symmetrical along the cardinal North-
South line to the azimuths of sunrises because we are close to the equator. The azimuths of sunrise/sunset at the equinoxes are, of course, 90 and 270 degrees.

In the mountains, we probably will not see sunrise/sunset at the theoretical zero horizon, but at some elevation angle (height) dictated by the local topography. We can compute the difference in the azimuth of such sunrise/sunset due to various elevations. For a model of local topography we make use of online digital terrain model Earth Remote Sensing Data Analysis Center, ASTER GDEM (2009), obtainable on: http://www.gdem.aster.ersdac.or.jp. The astronomical azimuth of the object is created from equations:

$$
\mathrm{A}_{\text {ast }}=\mathrm{A}_{\mathrm{mag}}+\delta
$$

\footnotetext{
* Corresponding author. This is useful to know for communication with the appropriate person in cases with more than one author.
} 
where:

$\mathrm{A}_{\text {mag }}=$ magnetic azimuth

$\delta=$ magnetic declination

Magnetic azimuth was measured by precise compass during the expedition in Peru in year 2012. With the compass we can measured with precision usually $\pm 1^{0}$. The magnetic declination was used from magnetic model NGDC - 720 (National Geophysical Data Centre's degree 720), which have information about magnetic field in all places in the World. In situation where we can't measure the magnetic azimuth, was the astronomical azimuth derived by means of Google Earth tools. Google Earth is very useful tool for study the historical areas (Pavelka at all., 2011). Possible inaccuracies were taken into account.

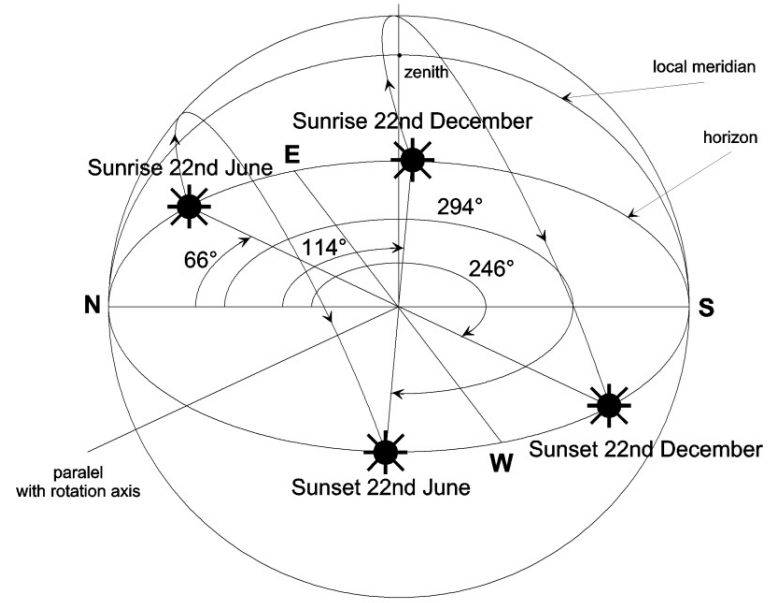

Figure 1: Astronomical azimuth of sunrise and sunset at the winter and summer solstice

\section{OLLANTAYTAMBO}

Ollantaytambo ( $\left.\varphi=13^{\circ} 15^{\prime} \mathrm{S} ; \lambda=72^{\circ} 16^{\prime} \mathrm{W}\right)$ is a small town with an archaeological area from the Incas period by Urubamba river near from Aquas Calientes, which is a starting point to Machu Picchu. By Protzen (1993), Zawaski and Malville (2007) or Salazar and Salazar (2005), we know some interesting information about orientation of Incas object in this area. Inticcahuarina (Incamisama) also Altar represents a solar watch. In this area, it isn't an exception. It was used to determining of time by Sun.

We focused on the Temple of the Sun, also Wall of six monoliths, in the upper part of areas. Temple of the Sun is a relatively large object with bright protrusions in the front. These projections suggest a solar orientation. We have investigated, which astronomical phenomenon is connected with the Temple.

\section{METHODS AND RESULTS}

We have astronomical azimuth of the wall of the Temple of the Sun $53^{\circ}$. We used the global digital elevation model ASTER GDEM and we created terrain profiles. The observation point was in the middle of the wall. It were created 19 profiles from north to east with the constant interval. On the basis of profiles was calculated the astronomical azimuth of sunrise on June solstice, $58-59^{\circ}$ or $32-31^{\circ}$ north of east.

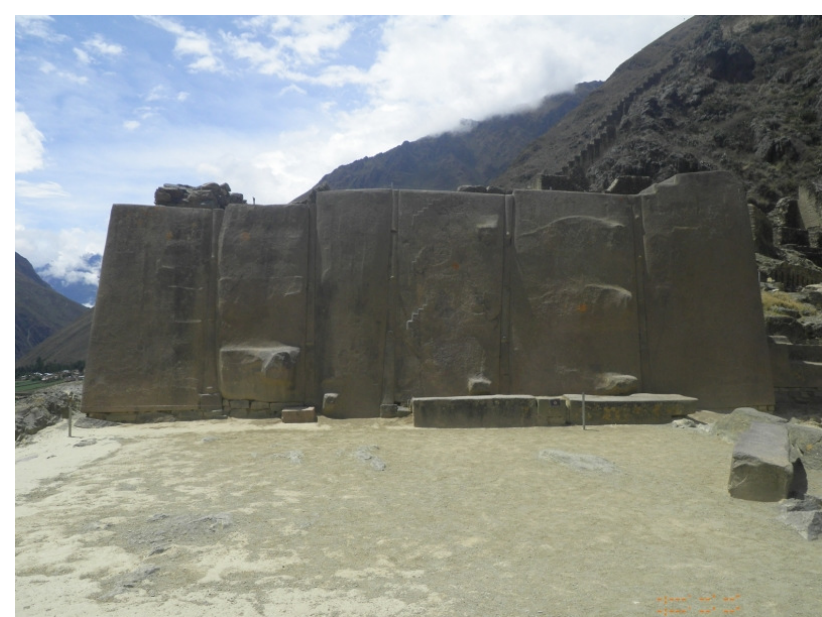

Figure 2: Wall of the six monoliths also known Temple of the Sun

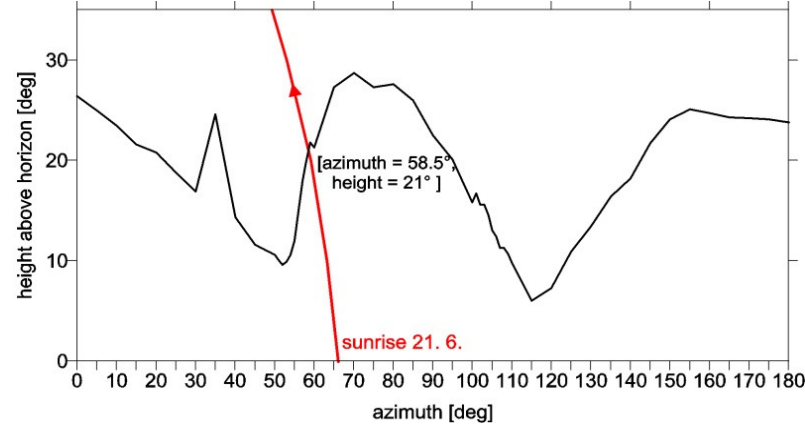

Figure 3: Altitude profile was created from DTM in direction from north to east. Observing point is Temple of the Sun. The red line shows sunrise at the winter solstice.

We compared the astronomical azimuth of the Temple of the Sun and the astronomical azimuth of sunrise. The Temple of the Sun is not observation point in conjunction with sunrise on June solstice.

We tested also the rise of the Pleiades, which have a similar declination as the Sun in June at the winter solstice. In the case of any stellar object, excluding the Sun, we have to account for the effect of precession. We computed sunrises of the Pleiades for the epochs 2000, 1500 and 1000 A.D. The astronomical azimuth is decreasing with time (see figure 4). The astronomical azimuth of the rise of Pleiades was about $62-64^{\circ}$ some 500 1000 years ago, but we need about $50^{\circ}$. Also we can't prove the astronomical orientation. We founded another possibility.

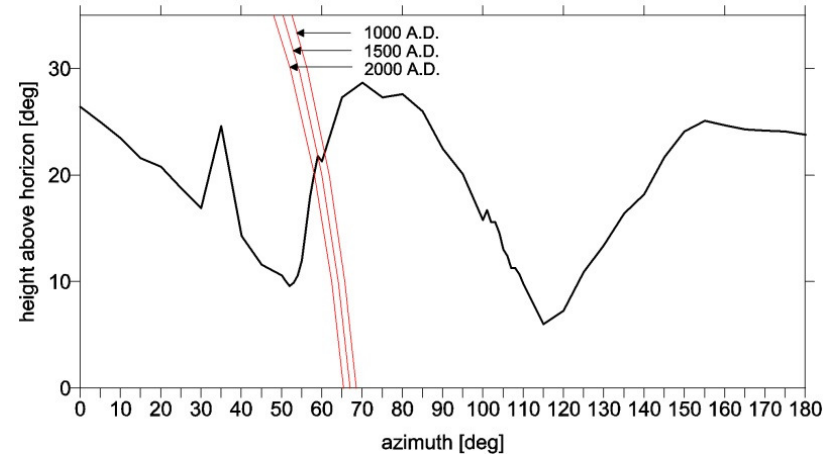

Figure 4: The rise of Pleiades in epochs 1000, 1500 and 2000 A.D. 
We tested directions west-north from an observation point near ruins of the Temple of Sun, in the direction to sunset. We computed the profile for the close mountains in direction westnorth. According to sunset at the winter solstice, the astronomical azimuth for height about $26^{\circ}$, is $305^{\circ}$, i.e. $55^{\circ}$ west of north (see figure 5). Again, the result was unsuccessfully.

We didn't accept a negative results. So we tried a possibility of another observation point. In year 2012, we were in Ollantaytambo and founded interesting ruins, which are up the hill $100 \mathrm{~m}$ over the Temple of the Sun (see figure 6). We tried to calculate the profile with observation point in this place, but also any success.

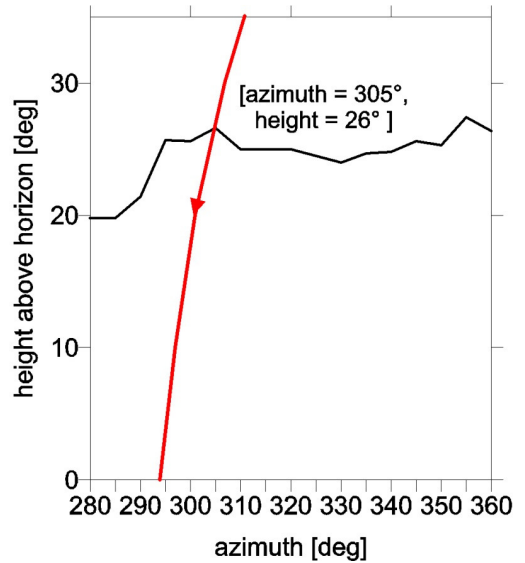

Figure 5: Altitude profile in direction from west to north for sunset.

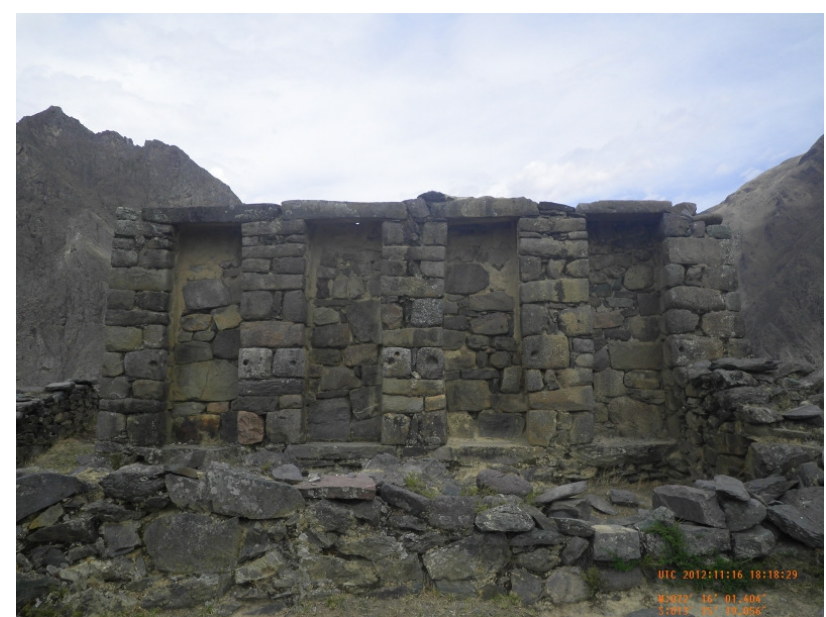

Figure 6: Ruins, 100 meter of height up the Temple of the Sun, view in east direction, (C) Hanzalová 2012

By Salazar and Salazar 2005, near from the Temple of the Sun, down by the riverside is a pyramid (see figure 7). We considered point $\mathrm{P}$, as observation point, at the corner (east rectangle) of the pyramid. There is a line connecting the east rectangular "platform" at the Urubamba river, going along the Inca road up to vicinity of the Temple of the Sun and then over the valley north of terraces and storehouses and the bearded man face in the direction to the Inca face.

The astronomical azimuth of this slant line is $62^{\circ}$. It was compare with azimuth from profile. The astronomical azimuth was calculated about $62-63^{\circ}$. Accounting for possible inaccuracy of both approaches, the conformity is excellent. It seems that we founded a solution.
By Salazar and Salazar 2005 the ray of sunlight falls in winter solstice to a corner of the pyramid. The chronicler Guamana Poma (1613) wrote that by means of sunshine falling on some windows the dates of sowing and harvest were estimated. Is this a random? By Salazar and Salazar 2005, we also try to calculate the western slope of the pyramid and sunrise at their summer solstice. The astronomical azimuth of this slant is $112^{\circ}$ derived by means of Google Earth tools. It was compare with the profile, which shows the azimuth about $112^{0}$. This results is also excellent. Now, we can confirm the astronomical-solarsolstice orientation in Ollantaytambo.

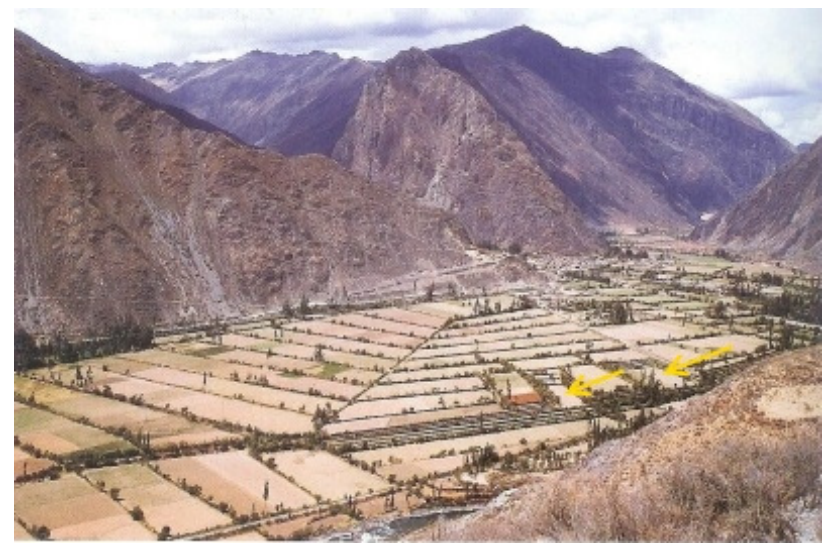

Figure 7: Pyramid with "windows". May be Temple? (C) Salazar and Salazar 2005

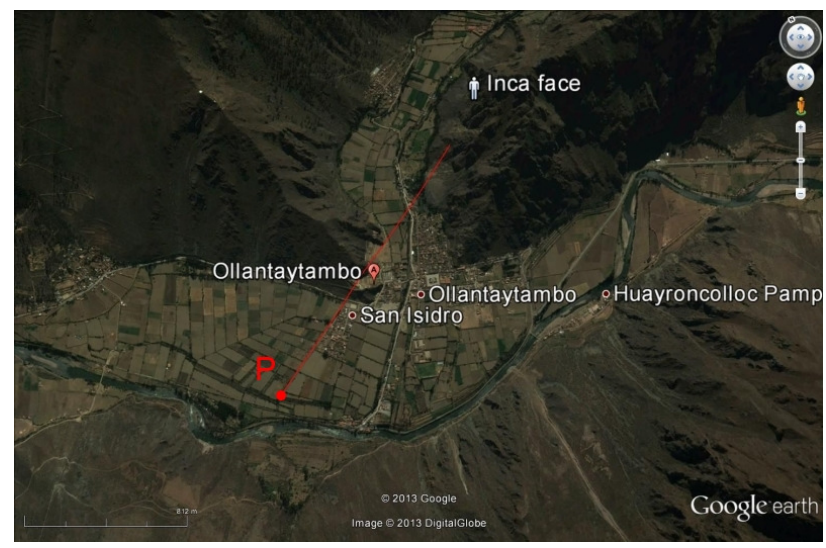

Figure 8: The line connecting pyramid, Temple of the Sun and Inca face in north-east direction. () Google Earth

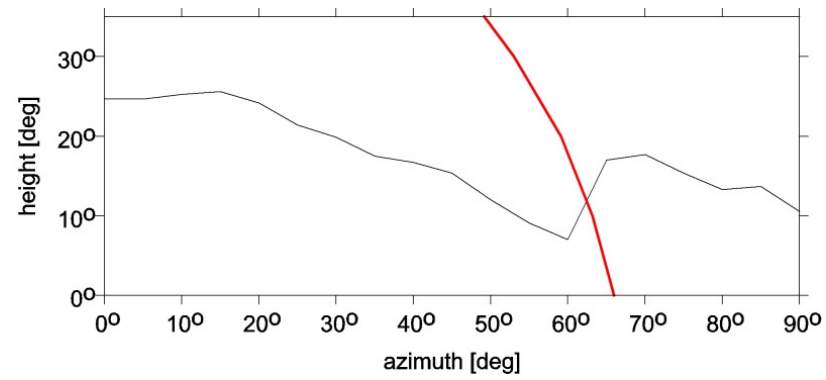

Figure 9: The terrain profile with observation point on the pyramid (point $\mathrm{P}$ ) in direction north to east for sunrise at winter solstice. 


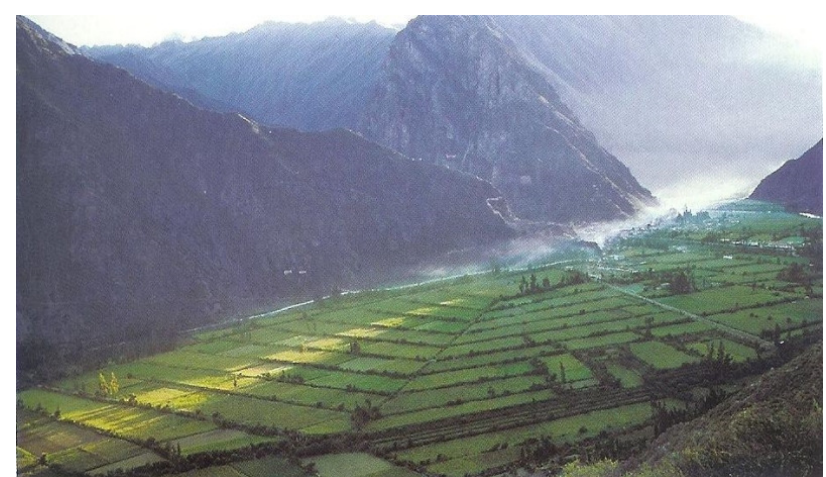

Figure 10: View on pyramid during the sunrise at summer solstice. () Salazar and Salazar 2005

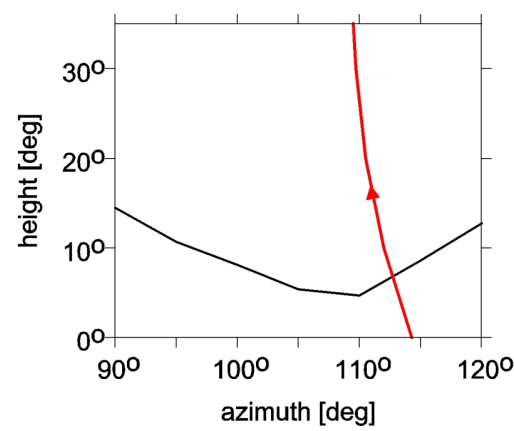

Figure 11: Terrain profile in direction west-south from pyramid. The red line shows the sunrise at summer solstice.

\section{CONCLUSION}

We tested astronomical solar orientation in Ollantaytambo, Peru. For determination of the astronomical azimuth of an object in mountains we need the digital elevation model, because the azimuth of the sunrise/sunset is not in theoretical zero horizon. For this work we used the online digital terrain model Earth Remote Sensing Data Analysis Centre, ASTER GDEM (2009). First, we focused on Temple of the Sun, also known as Wall of six monoliths. We tested astronomical azimuth of sunrise and sunset with observation point by the Temple of the Sun. The wall of Temple directed roughly to the rise of Sun and have astronomical azimuth about $50^{\circ}$. But the astronomical solar orientation wasn't confirm, because the astronomical azimuth of sunrise at their winter solstice is about $60^{\circ}$. Then, we tested also the rise of Pleiades in epochs 1000 , 1500 and 2000 A.D. Again, the result was unsuccessfully. We tried also the astronomical orientation of the ruins, which we founded $100 \mathrm{~m}$ up the hill, from the Temple. The ruins aren't connected with solar orientation. Then, by Salazar and Salazar 2005 we focused on pyramid near from the Temple of the Sun, down by the riverside. We founded the line that is connected the pyramid, Temple of the Sun and Incas face. In this direction the sun rises. The astronomical azimuth of sunrise at winter solstice in real horizon is about $62-63^{\circ}$. In compare with astronomical azimuth of the slant line, which is $62^{\circ}$, it was excellent result. After that, we also tried to calculate the astronomical azimuth of western slope of the pyramid at summer solstice. It came also excellent result. Both of the azimuths are $112^{\circ}$. Finally, we prove the astronomical solar orientation in Ollantaytambo. We can't exactly focus on the Temple of the Sun. The main object which is connected with Sun is the pyramid. About this pyramid we don't read many, excepting Salazar and Salazar 2005, there are many picture, which connect the pyramid with the Sun. The accuracy of these results, depend on the used method, is good. To refine of results we used the digital elevation model, because the terrain in Ollantaytambo is hilly and we need the astronomical azimuth of really horizon. The magnetic azimuths of the object were measured by precise compass with precision usually $\pm 1^{0}$. If wasn't possible to measured magnetic azimuth by compass, we use satellite images from Google Earth. There is possible to derive by means of Google Earth tools. Our results are new knowledge in research of astronomical orientation of the Incas object in Ollantaytambo, Peru. In this work was very useful digital elevation model, without which we don't found gut results. It is a very gut example that the remote sensing have very important role in archaeoastronomy.

\section{REFERENCES}

Earth Remote Sensing Data Analysis Center, ASTER GDEM 2009, obtainable on: http://gdem.ersdac.jspacesystems.or.jp.

Gullberg, Steven, R. Inca Solar Orientation in Southeastern Peru. Journal of Cosmology, 2010, 9: 2078-2091.

Malville, McKim, J., Cosmology in the Inca Empire: Huaca Sanctuaries, State-Supported Pilgrimage, and Astronomy. Journal of Cosmology, 2010, 9: 2106-2120.

Maus, Stefan. Degree - 720 ellipsoidal harmonic Model. National Geophysical Data Center, 2010, http://www.ngdc.noaa.gov/geomag-web/\#declination, (16. 4. 2014)

Pavelka, K., Klokočník, J., Kostelecký, J.: Astronomickohistorické otazníky Mezoameriky a Peru. ČVUT, 2013, 288s. ISBN: 9788001052198

Pavelka, K., Klokočník, J., Kostelecký, J.: Google Earth: Inspiration and Instrument for the Study of Ancient Civilizations. Geoinformatics CTU FCE. ISSN 1802-2669, vol. 6, no. 6, 2011,pp. 193-210.

Internet: http://geoinformatics.fsv.cvut.cz.

Protzen, Jean-Pierre. Inca Architecture and Construction at Ollantaytambo. Oxford University Press, USA. 1993, Published by: Maney Publishing. ISSN: 00934690

Salazar Elorrieta Fernando E. a Elorrieta Edgar E. Salazar. Cusco and the Sacred Valley of the Incas. Tankar E.I.R.L., Lima, 2005. ISBN: 978-603-45091-3-9.

Zawaski, M. J. a J. Malville Mckim. An Archaeoastronomical Survey of Major Inca Sites in Peru, Archaeoastronomy. 2007, Vol. 29, pp. 20-38. 